\title{
Hambatan Rebranding Boyband Dragonboyz dalam Industri Musik
}

\section{di Indonesia}

\author{
Lukas Pujianto, Sinta Paramita \\ Lukas.915150202@stu.untar.ac.id,Sintap@fikom.untar.ac.id
}

Fakultas Ilmu Komunikasi Universitas Tarumanagara

\begin{abstract}
This research is about rebranding boyband Dragoboyz obstacles in Indonesia's music industry. Rebranding is efforts made by a company or institution to totally change or renew a brand that has been there before to get better again. This condition is done by Dragonboyz as a boyband to have better and positive image than before in people's mind who loves musics, specially who loves boyband. But in the process of rebranding there are obstacles that stopped the rebranding process of Dragonboyz boyband. Conclusion from this research are obstacles to the rebranding process of Dragonboyz boy band can happen in Indonesia's music industry. This research uses qualitative descriptive method and cases studies. The subject for this research is Dragonboyz boyband. The Object from this rsearch is Rebranding obstacle in Indonesia's music.
\end{abstract}

Keywords: Dragonboyz, Music Industry, Obstacle, Rebranding,

\begin{abstract}
Abstrak
Penelitian ini berjudul, hambatan rebranding boyband Dragonboyz dalam industri musik di Indonesia. Perubahan merek (rebranding) yaitu merupakan upaya yang dilakukan oleh suatu perusahaan atau lembaga untukn merubah total atau memperbaharui kembali sebuah brand yang telah ada sebelumnya agar kembali menjadi lebih baik. Kondisi inilah yang dilakukan oleh sebuah grup boyband Dragonboyz yaitu untuk memperbaiki citra atau nama brandnya sendiri sehingga kembali menjadi lebih baik dari sebelumnya dan tercipta kembali citra positif yang baru dibenak para penikmat musik yang ada terutama pada kalangan pecinta boyband. Namun pada tahap rebranding terdapat hambatan yang mempengaruhi proses rebranding tersebut yang membuat terhentinya proses rebranding boyband Dragonboyz akibat hambatan-hambatan yang dialami selama proses berlangsung. Kesimpulan dari penelitian ini adalah mengetahui hambatan apa yan timbul dan bagaimana hambatan pada proses rebranding boyband Dragonboyz dalam industri musik itu bisa terjadi, dengan menggunakan penelitian kualitatif deskriptif. Pendekatan yang digunakan dalam penelitian ini adalah kualitatif deskriptif, dan jenis studi kasus. Subjek penelitian pada skripsi ini adalah boyband Dragonboyz. Sedangkan objek penelitian pada skripsi ini adalah hambatan rebranding dalam Industri musik Indonesia.
\end{abstract}

Kata Kunci: Dragonboyz, Hambatan, Industri Musik, Rebranding.

\section{Pendahuluan}

Perkembangan industri musik di Indonesia saat ini dinilai semakin bertumbuh dan berkembang sepanjang tahun 2017 hingga tahun 2018 saat ini. Tidak hanya pada musik pop yang selalu menjadi bagian dari penikmat musik di Indonesia kini genre lain pun mulai mengeluarkan kekuatannya masing-masing pada industri musik di Indonesia dan mulai menarik perhatian para penikmat musik. 
Salah satu jenis musik yang saat ini tengah menjadi perhatian pecinta musik di Indonesia adalah musik K-Pop, aliran musik yang berasal dari Korea Selatan ini sudah mewabah di Indonesia terutama boyband dan girlband yang berasal dari negeri ginseng tersebut semakin meluas dan dinikmati oleh semua kalangan masyarakat pun menyukai boyband dan girlband yang berasal dari Korea Selatan, korea memang berhasil mencipatakan market baru yang kuat sehingga boyband dan girlband menjadi ciri khas industri musik yang ada disana dan berhasil menarik perhatian di berbagai negara.

Keberhasilan industri musik korea selatan ternyata dapat terlihat dari kesuksesannya mereka menarik perhatian penggemar musik K-Pop yang kini hampir ada di beberapa negara termasuk Indonesia sendiri dapat terlihat dari para penggemar boyband dan girlband di Indonesia semakin banyak. Kehadiran boyband dan girlband Korea tersebut membuat industri musik Indonesia pun mencoba mengikuti jejak mereka dengan membuat segmen baru dalam industri musik di Indonesia dengan menghadirkan boyband dan girlband dari Indonesia sendiri. Salah satu boyband yang pernah hadir di Indonesia sendiri adalah boyband Dragonboyz.

Boyband Dragonboyz sebelumnya sudah terbentuk pada tahun 2011 dengan beranggotakan lima personel yang berasal dari kota Bandung. Dimana terbentuknya boyband Dragonboyz ini melalui tahap audisi yang dilakukan langsung oleh Sunnu (Matta Band) yang juga sebagai produser dan pembentuk dari boyband Dragonboyz sendiri.

Seperti yang publik ketahui, bahwa masyarakat di Indonesia pada umumnya memiliki image dan persepsi mengenai boyband dan girlband yang ada di Indonesia saat ini hanya merupakan sekumpulan anak perempuan atau laki-laki yang hanya menjual penampilan dan dance mereka, tanpa mereka bisa bernyanyi. Kurangnya pemahaman publik terhadap penyusunan strategi yang ada, seringkali membuat publik menganggap remeh atau memandang secara sebelah mata mengenai keberadaan boyband dan girlband yang ada di dalam industri musik Indonesia pada saat itu.

Karena itu rebranding yang akan dilakukan boyband Dragonboyz diharapkan dapat memberikan nuansa baru dalam industri musik Indonesia serta dapat diterima oleh publik dan penikmat musik saat ini.

Maka dari itu, penulis melakukan penelitian mengenai "Hambatan Rebranding Boyband Dragonboyz dalam Industri Musik di Indonesia"

Dalam penelitian ini, peneliti menggunakan beberapa teori yaitu;

Komunikasi Pemasaran

Menurut Kotler dan Keller (2009: 510) Komunikasi pemasaran merupakan salah satu usaha yang dilakukan oleh perusahaan untuk menginformasikan, membujuk, dan mengingatkan konsumen baik secara langsung maupun tidak langsung terhadap produk dan merek yang dijual. Untuk berkomunikasi secara efektif, pemasar perlu memahami sembilan unsur-unsur fundamental yang mendasari komunikasi yang efektif yang melibatkan: (1) sender, (2) encoding, (3) message, (4) media, (5) decoding, (6) receiver, (7) response, (8) feedback, dan (9) noise. Pihak yang berperan dalam komunikasi adalah sender dan receiver. Message dan media merupakan dua alat komunikasi yang utama. Terdapat empat fungsi komunikasi yang utama adalah encoding, decoding, response, dan feedback, dan yang terakhir adalah noise. 
Sender merupakan peran yang mengirmkan pesan kepada tujuan sasaran dan bertujuan untuk mengembangkan tujuan komunikasi. Encoding adalah proses komunikator atau pengirim pesan (sender) mengirimkan pesan dan tujuan komunikasi kepada penerima atau receiver. Message adalah pesan yang akan disampaikan oleh sender kepada receiver. Media merupakan sarana yang digunakan untuk menyampaikan pesan. Decoding adalah proses untuk memahami atau proses penerjemahan kembali pesan yang tealh diterima melalui media. Receiver adalah seseorang yang menerima pesan atau bisa disebut sebagai komunikan. Response adalah tanggapan dari receiver akan suatu pesan. Feedback adalah umpan balik dari suatu proses komunikasi.

Terdapat delapan bauran komunikasi pemasaran, di antaranya iklan, promosi penjualan, hubungan masyarakat dan publisitas, pemasaran langsung, pemasaran interaktif, pemasaran dari mulut ke mulut, penjualan personal. Kesemuanya adalah sarana untuk menyampaikan sesuatu melalui media Kotler dan Keller (2009: 174).

Rebranding

Kotler dan Keller (2009: 276) Brand sebagai simbol untuk membedakan suatu merek dari produk atau jasa yang diberikan agar dapat mengetahui masing-masing brand yang keluarkan dan dapat dibedakan satu sama lain.

Branding menurut Kotler dan Keller (2009: 278) adalah kegiatan memperkenalkan suatu barang atau jasa, dan memberikan kesan perbedaan antara barang dan jasa tersebut dengan cara memberikan nama dan elemn-elemen yang berbeda. dalam branding ini diharapkan dapat mengatur sesuatu yang lebih baik.

Rebranding merupakan suatu metode, strategi dan cara yang digunakan untuk memperkenalkan kembali suatu brand. Aplikasi strategi rebranding telah meluas, terutama dalam dua kategori pokok: (1) Manajemen merek strategik, yang memfokuskan brand valuation pada audiens internal berupa penyediaan alat dan proses untuk mengelola dan meningkatkan nilai ekonomik merek; dan (2) Transaksi finansial, menyangkut fasilitasi berbagai transaksi suatu brand dengan pihak-pihak eksternal (Tjiptono, 2011).

Tevi and Otubanjo (2013:89) American Marketing Association (AMA), Muzellec et al mendefinisikan rebranding sebagai sebuah nama, simbol, istilah serta gambaran tertentu yang dibentuk untuk membangun kembali brand ataupun merek dengan tujuan untuk membedakan posisi perusahaan yang baru di benak masyarakat, para pemangku kepentingan, dan pesaing.

Faktor dilakukannya rebranding dilatarbelakangi oleh faktor internal, diantaranya adanya perubahan struktur serta kepemilikan perusahaan, adanya keinginan terhadap peningkatan merek suatu perusahaan akibat reputasi yang buruk atau menurun di mata masyarakat lewat pembenahan dalam perusahaan, mempersatukan perusahaan di belakang salah satu merek lainnya, membentuk kembali dan juga menanamkan visi, misi dan nilai yang baru terhadap merek agar dapat lebih mewakili pelayanan dari perusahaan.

Faktor dilakukan rebranding juga dapat akibat merger dengan perusahaan lain, akuisisi, citra merek yang sudah kuno, atau ingin menunjukkan citra suatu kegiatan tanggung jawab sosial kepada masyarakat. Sedangkan faktor eksternal dilakukannya rebranding dilatarbelakangi oleh persepsi dari masyarakat tentang perusahaan, lingkungan bisnis yang semakin kompetitif, serta adanya penurunan kinerja dari perusahaan akibat dari perubahan kondisi ekonomi, sosial dan hukum.

Proses rebranding menurut Goi and Goi (2011:447) terbagi menjadi empat langkah berikut : (1) Mengidentifikasi alasan-alasan perusahaan untuk melakukan 
rebranding. (2) Mengevaluasi kekurangan dari merek awal. (3) Mengidentifikasi tujuan dilakukannya rebranding. (4) Mengendalikan dan mengawasi keterlibatan tim dalam manajemen kegiatan rebranding.

Tujuan perusahaan untuk melakukan rebranding adalah memperbaiki serta meningkatkan citra dan membentuk suatu identitas baru bagi perusahaan. Dalam proses rebranding, perlu meningkatkan keterlibatan karyawan internal serta para pemegang kepentingan eksternal dalam pembentukan citra.

Tahapan dari proses rebranding terdiri dari 4 tahap, yaitu:

1. Repositioning : pemberian makna atau posisi baru pada sebuah merek (brand) yang sudah ada, diantaranya dengan cara memperbaiki produk atau jasa yang ditawarkan tanpa mengubah nama dari brand atau merek.

2. Renaming : mengacu pada tindakan perusahaan membuat nama baru yang dipilih dan diadopsi untuk digunakan.

3. Redesign : inti dari filosofi perusahaan serta atribut utama dari produk atau merek yang digambarkan ke dalam sebuah simbol.

4. Relaunching : cara perusahaan untuk mengkomunikasikan kembali brand atau merek yang baru pada para stakeholder.

Menurut Ruslan hambatan komunikasi merupakan sesuatu hal yang menghalangi penerima menerima pesan. Terdapat empat bentuk hambatan komunikasi yaitu hambatan fisik (Physical Barriers), hambatan fisiologis (Physiological Barriers), hambatan psikologis (Psychological Barriers), dan hambatan semantik (Semantic Barriers) (2008: h. 9-10).

\section{Metode Penelitian}

Penelitian yang dilakukan oleh penulis bertujuan untuk mengetahui hambatan rebranding boyband Dragonboyz dalam industri musik di Indonesia. Jenis penelitian yang dilakukan adalah penelitian kualitatif secara deskriptif. Menurut Robert C. Bogdan dan Steven J. Taylor dalam buku Moleong menjelaskan metode penelitian kualitatif merupakan metode penelitian yang menghasilkan data yang bersifat deskriptif berupa kata-kata tertulis maupun lisan dari orang-orang dan perilaku yang diamati (Bogdan dan Taylor, dalam Moleong, 2012: 4).

Pendekatan metode kualitatif yang digunakan dalam penelitian ini adalah studi kasus. Fokus dari studi kasus adalah mengembangkan deskripsi mendalam dan menganalisa satu atau beberapa kasus (Creswell, 2013). Menurut Maxfield (1930), definisi dari studi kasus adalah penelitian tentang status subjek penelitian yang berkenan dengan suatu fase spesifik atau khas dari keseluruhan personalitas.

Moleong dalam bukunya mendeskripsikan subjek penelitian adalah orang pada latar penelitian untuk memberikan informasi tentang situasi dan kondisi latar penelitian (Moleong, 2012: 132). Berdasarkan pengertian tersebut subjek penelitian penulis adalah Boyband Dragonboyz.

Sugiyono dalam bukunya menjelaskan bahwa objek penelitian merupakan atribut atau sifat dari orang. Objek atau kegiatan yang memiliki variasi tertentu yang ditetapkan oleh peneliti untuk dipelajari dan kemudian ditarik kesimpulannya (Sugiyono, 2011: 20). Dalam penelitian ini yang menjadi objek penelitian adalah hambatan di dalam Industri musik Indonesia. 
Dalam penelitian ini data-data yang diperlukan penulis diperoleh berdasarkan metode pengumpulan data dengan cara-cara sebagai berikut :

1. Wawancara : Berdasarkan pemaparan di atas, penulis melakukan wawancara dengan beberapa narasumber di antaranya meliputi produser musik yang sudah paham dan mengerti kondisi musik yang ada di Indonesia serta salah satu musisi yang pernah terjun langsung di industri musik di Indonesia, sebagai produser musik, personel boyband Dragonboyz, dan penikmat musik Indonesia.

2. Observasi : Dalam hal ini penulis melakukan observasi melalui pengamatan yang penulis lihat dan juga mendengar secara langsung di tempat penelitian dan berdasarkan pendapat, penilaian, perasaan, harapan, serta respons narasumber yang berkaitan dengan pengalamannya terhadap objek penelitian yaitu Hambatan di dalam Industri Musik Indonesia.

3. Studi Kepustakaan : Dalam penelitian ini penulis memanfaatkan buku-buku bacaan yang berkaitan dengan teori Ilmu Komunikasi, masalah penelitian yang sesuai dengan penelitian, serta metode penelitian sebagai sumber data dan landasan teori yang mendukung penelitian ini.

4. Penelusuran Data Online : Dalam penelitian ini penulis menggunakan sumber online sebagai data pendukung atau tambahan untuk kebutuhan informasi penelitian.

Teknik Analisis Data: Menurut Bodgan \& Biklen dalam Moleong (2006:248) mendifinisikan analisis data kualitatif adalah analisis yang dilakukan dengan mengorganisasikan data, memilah-milahnya menjadi sebuah satuan yang dapat dikelola, mencari dan menemukan pola, memutuskan apa yang dapat diceritakan kepada orang lain dan menemukan apa yang penting dan apa yang dipelajari. Sedangkan menurut Seidel dalam Moleong (2006: 248) analisis data kualitatif prosesnya berjalan sebagai berikut :

a. Mencatat dari hasil lapangan, dalam hal ini diberi kode agar sumber datanya tetap dapat ditelusuri.

b. Mengumpulkan, memilah, mengklasifikasikan, mensintesiskan, membuat ikhtisar, serta membuat indeksnya.

c. Berpikir, dengan jalan membuat agar kategori data itu mempunyai makna, mencari dan menemukan pola dan hubungan-hubungan dan membuat temuan-temuan.

Berdasarkan pendapat diatas, maka rencana teknik analisis data yang dilakukan peneliti adalah:

a. Mentranskrip hasil wawancara yang telah direkam

b. Mengumpulkan, memilah-milah, dan mengklasifikasi hasil dari wawancara

c. Melakukan pemeriksaan data yang didapat, melakukan pengecekkan atas hasil yang telah didapat dan melakukan interpretasi hasil wawancara sehingga peneliti mendapatkan hasil penelitian.

\section{Hasil Temuan dan Diskusi}

Dalam prosesnya dapat disimpulkan, hasil dari rebranding harus menimbulkan dampak positif terhadap boyband Dragonboyz, serta brand image yang akan terbentuk haruslah secara matang dipersiapkan sebaik mungkin, mulai dari dukungan secara moral, materi, dan sebagainya. Proses yang harus terorganisir dengan baik 
dengan tujuan yang jelas dan satu visi dan misi dari masing-masing anggota boyband, tidak bias dipungkiri kehadiran boyband di era tahun 2011 sangatlah menggebrak panggung hiburan musik tanah air, namun disayangkan penulis menyimpulkan hanya bersifat tren atau sementara hingga pada tahun 2015 boyband mulai mengalami kemunduran yang drastis. Masing-masing dari personel boyband mulai keluar dari grupnya masing-masing yang membuat boyband di Indonesia terus berkurang sampai saat ini, dibutuhkan kesiapan yang matang secara mental agar boyband di Indonesia dapat bertahan dan menarik perhatian para penggemar boyband Korea yang justru lebih banyak digemari di Indonesia di banding boyband Indonesia sendiri. Timbulnya perbedaan visi dan misi yang dihadapi masing-masing personel diakibatkan adanya hambatan-hambatan yang mulai muncul di antaranya:

a. Anggota boyband Dragonboyz yang mulai berkurang, yang sebelumnya terdiri dari lima personel kini berkurang dua orang, sehingga saat ini tersisa tiga orang.

b. Pembagian fee yang didapat oleh setiap personel kurang sesuai dengan yang diperkirakan oleh masing-masing personel. Seperti penghasilan dari on air yang hanya dibayar dengan ongkos transportasi. Namun pengeluaran yang dikeluarkan oleh masing-masing personel dirasa kurang sesuai dengan penghasilan yang selama ini didapat oleh Dragonboyz.

c. Kurangnya dukungan dari managemen terhadap rebranding yang akan dilakukan oleh Dragonboyz sendiri, perlunya kerja sama antara Dragonboyz dan managemen dalam melakukan rebranding ini.

d. Berkurangnya peminat boyband dan girlband di Indonesia. Peminat di Indonesia sendiri lebih banyak menyukai genre dangdut, dan lebih banyak penggemar Kpop dibanding penggemar boyband Indonesia sendiri.

Dan pada pada penelitian ini penulis menemukan kekuatan pada boyband ini diantaranya:

a. Kekompakan dalam dance mereka yang dari awal terbentuk sudah terlihat kekompakannya.

b. Konsep baru yang dimiliki oleh boyband Dragonboyz berbeda dengan konsep Dragonboyz di awal debut.

Kelemahan pada boyband ini:

a. Kurangnya niat untuk latihan

b. Memiliki kesibukan masing-masing

Namun penulis melihat adanya kesempatan yang baik bagi Dragonboyz untuk melakukan rebranding. Kurangnya peminat musik boyband yang jauh dibanding sebelumnya merupakan ancaman yang harus dihadapi boyband Dragonboyz.

\section{Simpulan}

Berdasarkan dengan rumusan masalah pada bab I bahwa terjawab sudah bahwa hambatan rebranding boyband Dragonboyz dalam Industri musik Indonesia adalah sebagai berikut:

1. Genre musik boyband dan girlband sangat terbatas untuk bisa di terima di Indonesia. Hal ini merupakan hambatan yahng paling utama pada kasus ini, karena di Indonesia sendiri musik atau genre yang paling digemari adalah musik atau genre dangdut dan grup band.

2. Sulitnya kembali menyatukan visi dan misi dari masing-masing personel boyband Dragonboyz. Perbedaan dari setiap visi dan misi dari masing-masing 
personil boyband Dragonboyz juga merupakan salah satu hal yang menjadi hambatan untuk boyband Dragonboyz melakukan rebranding kembali pada industri musik Indonesia.

3. Industri yang musiman dan hanya mengikuti tren. Kemunculan boyband di Indonesia pada tahun 2011 lalu adalah awal dimulainya kejayaan boyband dan Girlband pada industri musik di Indonesia, salah satu faktor penyebabnya juga disaat musik K-Pop (Korean Pop) tengah melonjak dan mulai masuk ke Indonesia.

4. Sulitnya menyamakan atau mengikuti kualitas boyband di Indonesia dengan Boyaband yang berasal dari Korea selatan. Dalam hal ini tidak dapat dipungkiri konsep yang dimiliki oleh boyband yang berasal dari Korea Selatan jauh lebih unik dan menarik dari konsep yang disuguhkan oleh boyband yang ada di Indonesia.

5. Penulis menyimpulkan bahwa hambatan rebranding boyband Dragonboyz dalam industri musik di Indonesia terjadi karena mulai berkurangnya penikmat musik boyband Indonesia sendiri yang tergeser oleh para penggemar musik K-Pop yang ada di Indonesia. Selain itu hall ini pun terjadi karena genre musik lain seperti dangdut yang sudah menjadi ciri khas dan memiliki penggemar lebih banyak di Indonesia.

\section{Ucapan Terimakasih}

Ucapan terimakasih ditunjukan kepada Tuhan Yang Maha Esa, Orang tua dan narasumber serta kepada teman-teman yang telah memberikan dukungan secara spiritual dan materil.

\section{Daftar Pustaka}

Bogdan dan Taylor. (2012). Prosedur Penelitian. Dalam Moleong, Pendekatan Kualitatif. Jakarta: Rineka Cipta.

Creswell, J.W. (2013). Research Design Pendekatan Kualitatif, Kuantitatif, dan Mixed, edisi ketiga. Yogyakarta: Pustaka pelajar.

Goi, CL dan Goi, MT, (2011). Review on Models and Reasons of Rebranding, International Conference on Social Science and Humanity. Singapore : Vol.5

Kotler dan Keller. (2009). Manajemen Pemasaran. Jilid I. Edisi ke 13. Jakarta: Erlangga

Moleong, Lexy J. (2012). Metodologi Penelitian Kualitatif. Bandung: PT Remaja Rosdakarya.

Ruslan,Rosady. (2008). Manajemen Public Relatoins \& Media Komunikasi. Jakarta : PT Rajagrafindo Persada.

Sugiyono. (2011). Metode Penelitian Kuantitatif, Kualitatif dan R\&D. Bandung: Afabeta

Tevi, AC dan Otubanjo, O. (2013). Understanding Corporate Rebranding: An Evolution Theory Perspective, International Journal of Marketing Studies. Vol.5, No.3

Tjiptono, Fandy. (2011). Manajemen dan Strategi Merek. Yogyakarta : Andi Offset Press. 